\title{
Overexpression of the $Y A P 1$ oncogene in clear cell renal cell carcinoma is associated with poor outcome
}

\author{
AGNIESZKA RYBARCZYK ${ }^{1}$, JAKUB KLACZ ${ }^{2}$, AGATA WRONSKA ${ }^{1}$, MARCIN MATUSZEWSKI $^{2}$, \\ ZBIGNIEW KMIEC $^{1}$ and PIOTR M. WIERZBICKI ${ }^{1}$ \\ ${ }^{1}$ Department of Histology, Faculty of Medicine, Medical University of Gdansk, 80211 Gdansk; \\ ${ }^{2}$ Department of Urology, Faculty of Medicine, Medical University of Gdansk, 80402 Gdansk, Poland
}

Received January 26, 2017; Accepted April 27, 2017

DOI: $10.3892 /$ or.2017.5642

\begin{abstract}
Clear cell renal cell carcinoma (ccRCC) is the most common subtype of RCC (70-80\%). Yes-associated protein 1 (YAP1) protein is a nuclear effector of the Hippo pathway and acts as a transcriptional co-activator of genes involved in the processes of growth and development of tissues.Hippo signaling, with its key kinases, MST2 and large tumor suppressor kinase 1 (LATS1), plays a significant role in the negative regulation of the amount and activity of YAP1 protein. Components of the Hippo pathway and YAP1 levels are frequently dysregulated in a variety of tumors, suggestive of their possible involvement in carcinogenesis. Our aim was to evaluate gene and protein expression profiles of YAP1, MST2 and LATS1 and the methylation status of MST2 and LATS1 promoters in ccRCC. mRNA levels of MST2, LATS1 and YAP1 genes were assessed in the tumor and matched normal kidney tissues of 86 patients, and in 12 samples of local metastases by quantitative PCR (qPCR). Proteins were semi-quantified in 58 patient samples by western blotting. Hypermethylation of LATS1 and MST2 promoters was measured by methylation-specific high-resolution-melting qPCR. We found that LATS1 promoter hypermethylation, decreased LATS1 mRNA/protein and increased YAP1 mRNA/protein levels in tumor samples were associated with higher TNM and Fuhrman's stages and patient survival. Higher YAP1 mRNA levels were associated with poor outcome $(\mathrm{HR}=4.03, \mathrm{p}=0.036)$. No changes in MST2 (promoter/ mRNA/protein) were found. We propose that deregulation of LATS1 and YAPl expression is associated with ccRCC progression and poor patient survival. Measurement of YAPl mRNA levels in paired tumor-normal kidney tissue samples may serve as a new prognostic factor in ccRCC.
\end{abstract}

Correspondence to: Dr Piotr M. Wierzbicki, Department of Histology, Faculty of Medicine, Medical University of Gdansk, 1 Debinki Street, 80211 Gdansk, Poland

E-mail: pwierzb@gumed.edu.pl

Key words: clear cell renal cell carcinoma, DNA methylation, gene expression, Hippo pathway, LATS1, metastatic disease, MST2, qPCR, prognosis, YAP1

\section{Introduction}

Clear cell renal cell carcinoma (ccRCC) is the most frequent RCC subtype and is characterized by a high mortality rate of $40 \%$ within 5 years, due to late diagnosis and distant metastases found in 30 (1) to $80 \%$ (2) of RCC patients at the time of examination or within the course of the disease. Among patients who undergo radical resection of the tumor, future metastatic disease develops in 20-40\% of the ccRCC cases (3). The search for new molecular targets is continuing due to the high mortality rate of advanced RCC patients (4).

The Hippo pathway is an important regulator of cell proliferation, apoptosis, stem cell functions $(5,6)$ as well as tissue growth and regeneration. Its deregulation is commonly observed in many human cancers, suggesting that alterations of Hippo signaling may be associated with tumor initiation and/or progression (7-9). The Hippo core cassette is formed by MST2 (serine/threonine kinase 3, STK3) and large tumor suppressor kinase 1 (LATS1) kinases (10). The phosphorylation of LATS1 by MST2 (with SAV1 and MOB1A/B co-activators) inhibits its transcriptional co-activator and downstream effector - Yes-associated protein 1 (YAP1) (11) via its phosphorylation, sequestration to the cytoplasm followed by YAP1 degradation $(4,12)$. When YAP1 is located in the nucleus, it interacts with several transcriptional factors including TEA domain transcription factor 1-4 (TEAD1-4), OCT4, TP73 and ZEB1 (13). Increased expression of the YAP1 protein is associated with tissue regeneration or carcinogenesis $(11,14,15)$. Moreover, the deregulation of the Hippo pathway components and/or YAP1 expression is frequently associated with the progression of various malignancies. Decreased expression of LATS1 gene and protein was observed in breast (16), colorectal (17) and non-small cell lung cancers (18), whereas lower MST2 mRNA and protein levels were reported in hepatocellular carcinoma (19) and malignant mesothelioma (20). Furthermore, the overexpression of YAP1 protein was observed in many cancer types, including lung (21), prostate (22), breast (23), and gallbladder cancers (24) and glioma (25). Since to date no quantitative analyses of the expression of the Hippo pathway effector, YAP1, and its key components, MST2 and LATS1 kinases, have been assessed in ccRCC, we decided to compare their mRNA and protein levels in tumor and normal kidney tissues, and in metastases of ccRCC. We also analyzed 
Table I. Clinicopathological features of the ccRCC patients and the association between YAP1, LATS1 and MST2 mRNA levels and clinical data.

\begin{tabular}{|c|c|c|c|c|c|c|c|c|c|}
\hline \multirow{2}{*}{$\begin{array}{l}\text { Patient } \\
\text { characteristics } \\
(\mathrm{n}=86)\end{array}$} & \multicolumn{3}{|c|}{ YAP1 qPCR results, n (\%) } & \multicolumn{3}{|c|}{ LATS1 qPCR results, $\mathrm{n}(\%)$} & \multicolumn{3}{|c|}{ MST2 qPCR results $\mathrm{n},(\%)$} \\
\hline & $\underset{(\leq 0.382)}{\text { Low }}$ & $\underset{(>0.382)}{\text { High }}$ & $\begin{array}{c}\text { P-value } \\
(\text { low vs. high })^{\mathrm{a}}\end{array}$ & $\underset{(\leq 1.982)}{\text { Low }}$ & $\underset{(>1.982)}{\text { High }}$ & $\begin{array}{c}\text { P-value } \\
(\text { low vs. high })^{a}\end{array}$ & $\underset{(\leq 0.539)}{\text { Low }}$ & $\underset{(>0.539)}{\text { High }}$ & $\begin{array}{c}\text { P-value } \\
\text { (low vs. high) }\end{array}$ \\
\hline \multicolumn{10}{|l|}{ Age (years) } \\
\hline \multicolumn{10}{|c|}{ Mean: $62.16 \pm 11.24$} \\
\hline \multicolumn{10}{|c|}{ Range: 33-83 } \\
\hline$\leq 62$ & $15(17)$ & $30(35)$ & 0.64 & $39(45)$ & $6(7)$ & 1.00 & $24(28)$ & $21(24)$ & 0.66 \\
\hline$>62$ & $11(13)$ & $30(35)$ & & $36(42)$ & $5(6)$ & & $19(22)$ & $22(26)$ & \\
\hline \multicolumn{10}{|l|}{ Sex } \\
\hline Female $(n=38)$ & $10(12)$ & $28(32)$ & 0.64 & $29(31)$ & $9(10)$ & 0.43 & $16(19)$ & $22(26)$ & 0.28 \\
\hline Male $(n=48)$ & $16(19)$ & $32(37)$ & & $46(49)$ & $2(10)$ & & $27(31)$ & $21(24)$ & \\
\hline \multicolumn{10}{|l|}{ Tumor size $(\mathrm{cm})$} \\
\hline$\leq 7(\mathrm{n}=50$ & $12(14)$ & $24(28)$ & 0.64 & $39(45)$ & $6(7)$ & 1.00 & $23(27)$ & $13(15)$ & 0.048 \\
\hline$>7(\mathrm{n}=36)$ & $14(16)$ & $36(42)$ & & $36(52)$ & $5(6)$ & & $20(23)$ & $30(35)$ & \\
\hline \multicolumn{10}{|c|}{$\begin{array}{l}\text { Fuhrman's } \\
\text { histological grade }\end{array}$} \\
\hline $1+2(\mathrm{n}=35)$ & $14(16)$ & $21(24)$ & 0.08 & $27(32)$ & $8(9)$ & 0.04 & $17(20)$ & $18(21)$ & 1.00 \\
\hline $3+4(n=51)$ & $12(14)$ & $39(45)$ & & $48(56)$ & $3(3)$ & & $26(30)$ & $25(29)$ & \\
\hline \multicolumn{10}{|l|}{ TNM stage } \\
\hline \multicolumn{10}{|l|}{ Non-metastatic } \\
\hline T1-2N0M0 & $21(24)$ & $16(19)$ & $<0.0001$ & $29(34)$ & $8(9)$ & 0.04 & $18(21)$ & $19(22)$ & 1.00 \\
\hline \multicolumn{10}{|l|}{ Metastatic } \\
\hline $\mathrm{T} 1-2 \mathrm{~N} 1 \mathrm{M} 0$ & $5(6)$ & $44(51)$ & & $46(53)$ & $3(3)$ & & $25(29)$ & $24(28)$ & \\
\hline \multicolumn{10}{|l|}{ T3N0-1M0 } \\
\hline \multicolumn{10}{|l|}{$\mathrm{T} 4 \mathrm{~N} 0-2 \mathrm{M} 0$} \\
\hline \multicolumn{10}{|l|}{$\mathrm{T} 1-4 \mathrm{~N} 2 \mathrm{M} 0$} \\
\hline T1-4N0-2M1 & & & & & & & & & \\
\hline
\end{tabular}

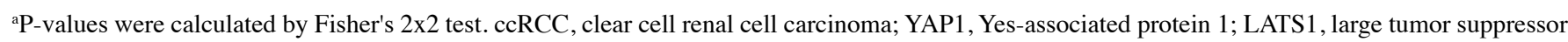
kinase 1; MST2, serine/threonine kinase 3. Bold indicates statistical significance.

the methylation status of LATS1 and MST2 gene promoters by methylation-specific high-resolution-melting quantitative PCR (MS-HRM-qPCR), a novel quantitative technique.

\section{Materials and methods}

Patients and samples. Tissue samples were collected from 86 ccRCC patients who underwent radical nephrectomy at the Department of Urology, Medical University of Gdansk, Poland, between January 2011 and September 2013. The clinical data of patients are presented in Table I. The study was approved by the local Ethics Committee; written consent was obtained before surgery from each patient.

Sample acquisition. Samples were obtained according to our previous reports $(26,27)$. In short, dissected tissue samples of primary ccRCC tumors ( $\mathrm{n}=86$, named $\mathrm{T})$, normal kidney ( $n=86$, named $\mathrm{C}$ as control) and adrenal gland or the whole lymph node $(n=12$, named $M)$, were collected in the operating theatre (by J.K.) and placed immediately in approximately five volumes of RNAlater (Ambion Inc., Austin, TX, USA).
Assessment of MST2, LATS1 and YAP1 mRNA expression. RNA isolation and cDNA synthesis were performed as previously described $(26,27)$. Briefly, ExtractMe RNA kit (DNAGdansk, Gdansk, Poland) was used for RNA extraction. Two micrograms of total RNA was reverse transcribed with the use of RevertAid Reverse Transcriptase (Fermentas-Thermo Fischer Scientific, Fitchburg, WI, USA). qPCR details are presented in Table II. All reactions were run in duplicate. Based on the results of our previous study on the choice of suitable qPCR reference gene in ccRCC (27), we chose the assessment of GUSB gene expression to normalize the mRNA levels in the samples with the use of Schmittgen and Livak's $\Delta \Delta \mathrm{Ct}$ equation (28).

DNA extraction, bisulfite modification, acquisition of control DNA and MS-HRM-qPCR. The methodology has been previously described (26). In short, DNA was isolated to a total volume of $20 \mu \mathrm{l}$ followed by bisulfide modification (DNA Methylation-Direct ${ }^{\mathrm{TM}}$ kit; Zymo Research, Irvine, CA, USA). For the generation of a dilution series of control DNA standards, fully methylated (named MD) and unmethylated (UMD) human genomic DNAs (Zymo) were used. 


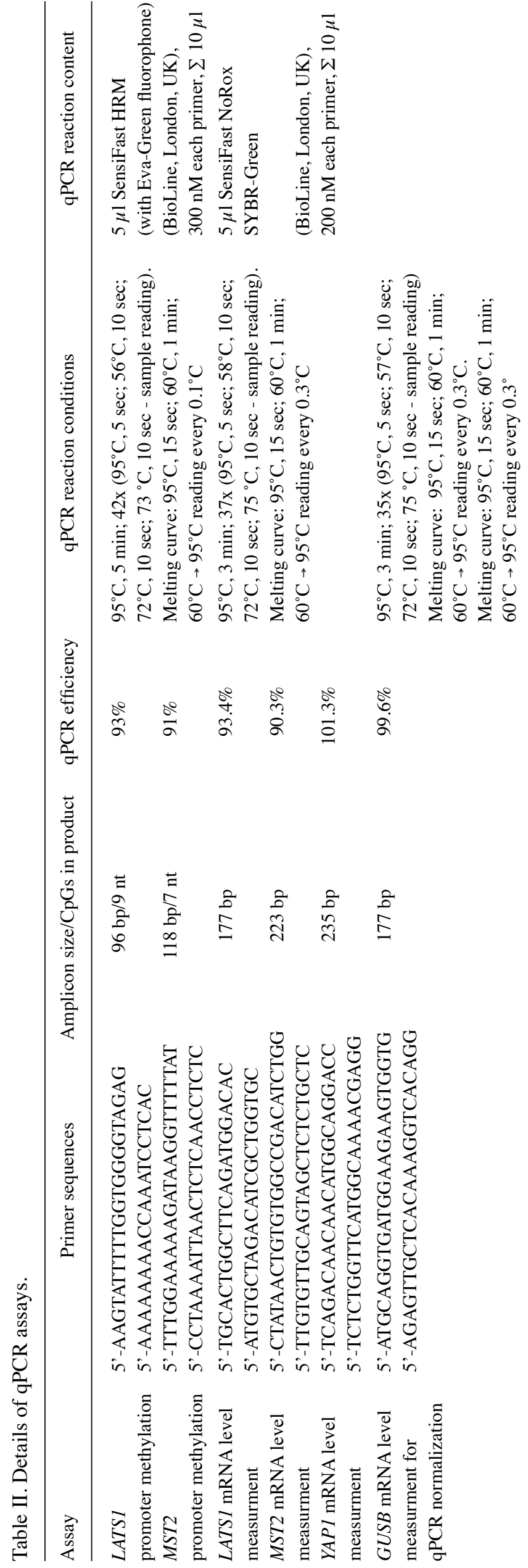

Methylation was assessed in the samples with the use of the MS-HRM-qPCR method (29). Reactions were set on the Step-One Plus apparatus, then post-PCR products were analyzed with the use of HRM software ver. 3.1 (both from Life Technologies, Grand Island, NY, USA). For each run, matched DNA from T, C and M samples were set; standard dilutions of control MD and UMD were made to 100, 50, 25, 10 and 0 of MD in UMD and used in the same PCR plate as well as the no template control.

Western blot analysis. Protein lysates were prepared with Mammalian Cell Extraction kit (BioVision, Milpitas, CA, USA). The lysates $(10 \mu \mathrm{g})$ were loaded onto a $10 \%$ Mini-Protean TGX gel (Bio-Rad, Hercules, CA, USA), resolved by SDS-PAGE, and transferred to a PVDF membrane using the Trans-Blot Turbo system (Bio-Rad). Membranes were stained with $0.1 \%$ Ponceau $\mathrm{S}$ to ensure equal loading after transfer, and subsequently blocked with 5\% albumin fraction V in TBS buffer with $0.1 \%$ Tween-20 (TBST) for $1 \mathrm{~h}$ at room temperature (RT). After washing with TBST, the membranes were incubated (overnight, $4^{\circ} \mathrm{C}$ ) with specific primary antibodies in $2 \%$ albumin/TBS: rabbit anti-LATS1 (1:2,000, Bioss, Woburn, MA, USA), rabbit polyclonal anti-YAP1 $(1: 1,000)$, and rabbit monoclonal anti-MST2(STK3) (1:2,000) (both from Abcam, Cambridge, UK) and anti-GAPDH peroxidase-conjugated $\operatorname{IgM}(1: 50,000$; Sigma-Aldrich, St. Louis, MO, USA). After triple washing with TBST, the blots were incubated for $2 \mathrm{~h}$ at RT with horseradish peroxidase-conjugated secondary antibodies: anti-rabbit IgG or anti-mouse IgG (1:15,000; Sigma-Aldrich). Following triple washing with TBST, immunoreactive bands were detected on medical X-ray film (Agfa HealthCare, Mortsel, Belgium) using chemiluminescent peroxidase substrate (Sigma-Aldrich). Densitometric analysis of immunoreactive protein bands was performed with Quantity One software (Bio-Rad) and calculated as units $=$ intensity $/ \mathrm{mm}^{2}$. After normalization to GAPDH protein units for each sample, the semi-quantitative results for either tumor or metastasized samples were obtained as a ratio: mean units $_{\mathrm{T} / \mathrm{M}} /$ mean units ${ }_{\mathrm{C}}$ for MST2, LATS1 or YAP1 proteins.

Statistical analysis. Statistical analysis was performed with the use of the GraphPad Prism ver. 6.05 software (GraphPad Software, San Diego, CA, USA). The following statistical tests were used: non-parametric Mann-Whitney U, Kruskal-Wallis ANOVA, Fisher's $2 \times 2$ exact test, multivariate regression, and Cox-Mantel proportional hazard regression model. Survival relationships were presented as hazard ratios (HR) with their 95 confidence interval (CI) and p-values (30) using Cox and Kaplan-Meier estimations. Rates of overall survival (OS) and progression-free survival (PFS) were calculated separately. In all analyses, a two-sided $\mathrm{p}<0.05$ was considered as statistically significant with a $95 \% \mathrm{CI}$.

\section{Results}

Clinicopathological characteristics of the patients. Of the 86 ccRCC patients $(62.1 \pm 11.2$ years, mean age \pm SD) (Table I), 37 were diagnosed as stage I (T1-2N0M0), 8 as stage II (T2N0M0), 12 as stage III (T1-2N1M0 or T3N0-1M0) and 29 as stage IV (T4N0-2M0 or T1-4N2M0 or T1-4N0-2M1). TNM stages of the kidney cancer are as follows: stage I, tumor 
A
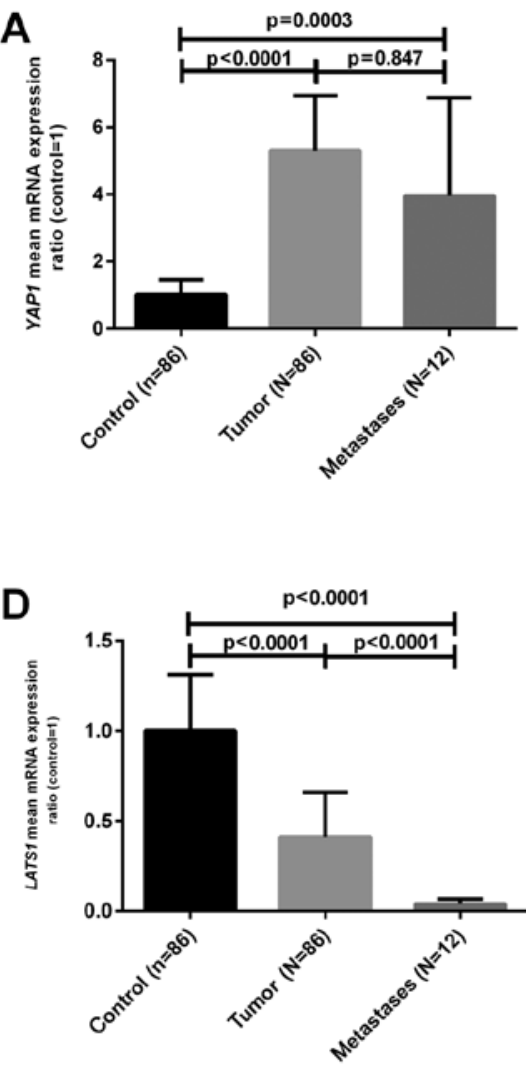

$\mathbf{G}$

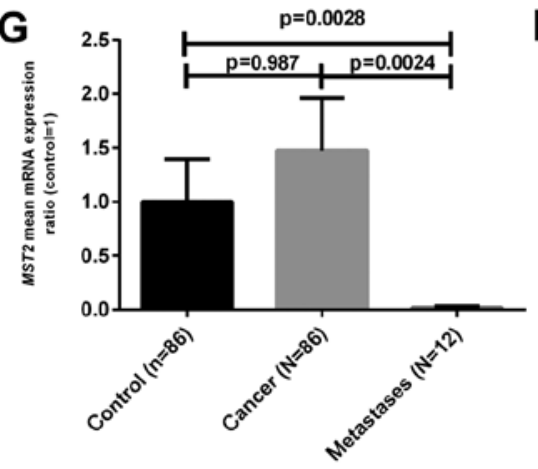

B

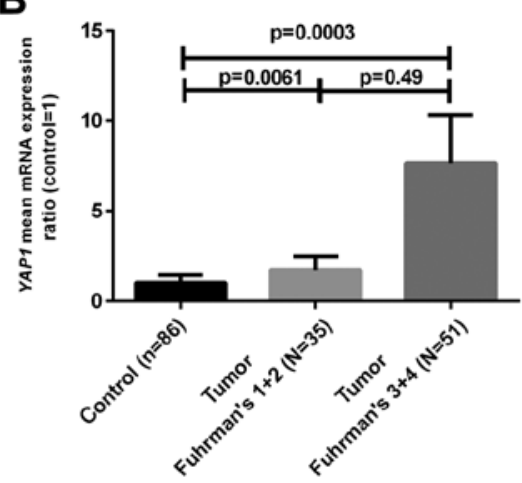

$\mathbf{E}$

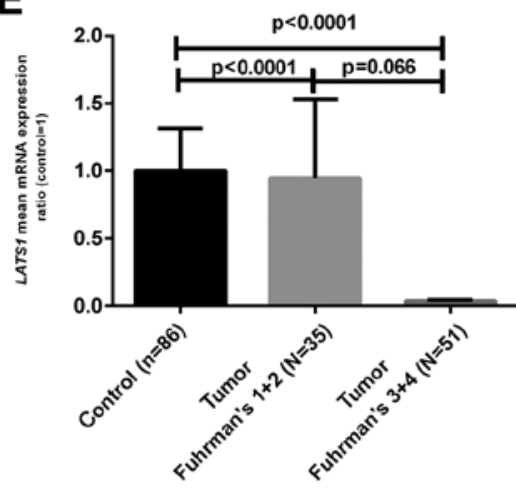

$\mathbf{H}$

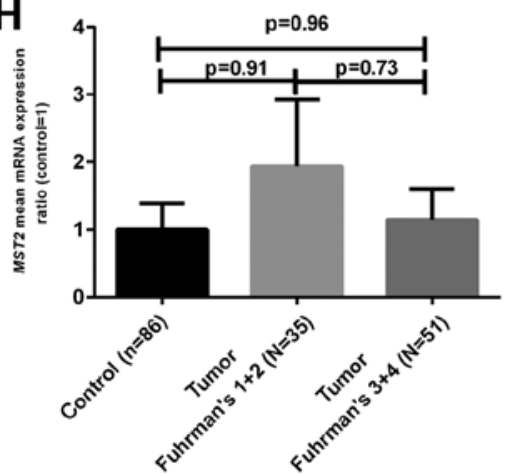

C

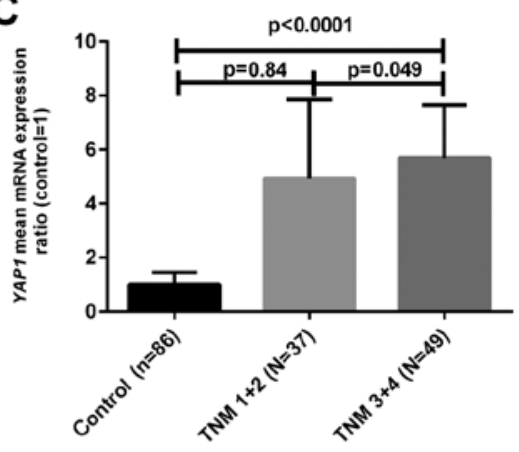

$\mathbf{F}$
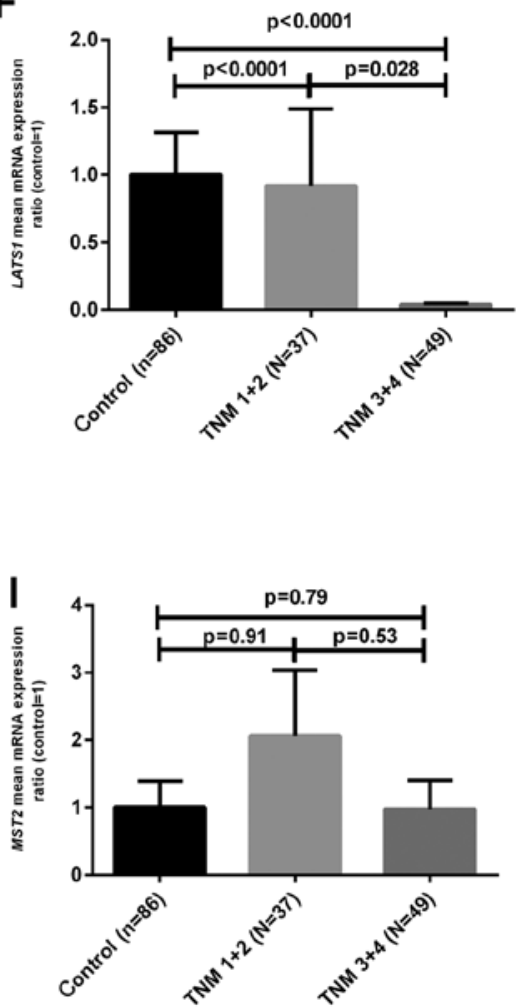

Figure 1. YAP1, LATS1 and MST2 gene expression in ccRCC. YAP1 (A), LATS1 (D) and MST2 (G) mRNA levels in tissue samples of ccRCC patients were assessed by qPCR as described in Materials and methods. Plots show gene expression in tumor samples related to Fuhrman's grading (B, E and H) and TNM (C, F and I). Bars and whiskers represent mean \pm SEM normalized to control kidney samples. P-values between groups (Mann-Whitney U test) are noted. ccRCC, clear-cell renal cell carcinoma; qPCR, quantitative PCR; LATS1, large tumor suppressor kinase 1; YAP1, Yes-associated protein 1.

$\leq 7 \mathrm{~cm}$ and limited to the kidney; stage II, tumor 7-10 $\mathrm{cm}$, limited to the kidney; stage III, tumor extends into major veins or perinephric tissues but not into the ipsilateral adrenal gland and not beyond Gerota fascia or T1-T3 with metastasis in a single regional lymph node; stage IV, metastasis in more than one regional lymph node or distant metastasis (31). At the time of surgery, $47.7 \%$ of the ccRCC patients were diagnosed with local or distant metastases. Histological nuclear staging in renal cancer is based on the Fuhrman grading; grade 1: small, round, uniform nuclei (10 microns), inconspicuous nucleoli; grade 2: slightly irregular nuclei, nuclear diameter 15 microns, open chromatin; grade 3: visible nucleoli, nuclei very irregular, diameter 20 microns, open chromatin (32). According to Fuhrman's division 4 patients were grade 1, 32 grade 2, 23 grade 3 and 26 were grade 4 . None of the patients underwent chemotherapy or radiotherapy before surgery. The mean follow-up period was 21 months (range, 3-48). To date, 45 patients were alive (52\%); all deaths (except for one patient) were related to ccRCC progression. Median OS rate was 12 months. During follow-up, metastases occurred in 38 (44\%) patients while the median PFS rate was 6 months.

Expression of the YAP1, LATS1 and MST2 genes at the mRNA level. As shown in Fig. 1A, YAPl mRNA levels in T (tumor) and $\mathrm{M}$ (metastatic) samples were $\sim 5$ and 4 times higher when compared to the $\mathrm{C}$ (control tissue) samples, respectively $(\mathrm{p}<0.01)$. When the samples were divided according to median mRNA values in the $\mathrm{C}$ samples, we found that 60 (70\%) out 

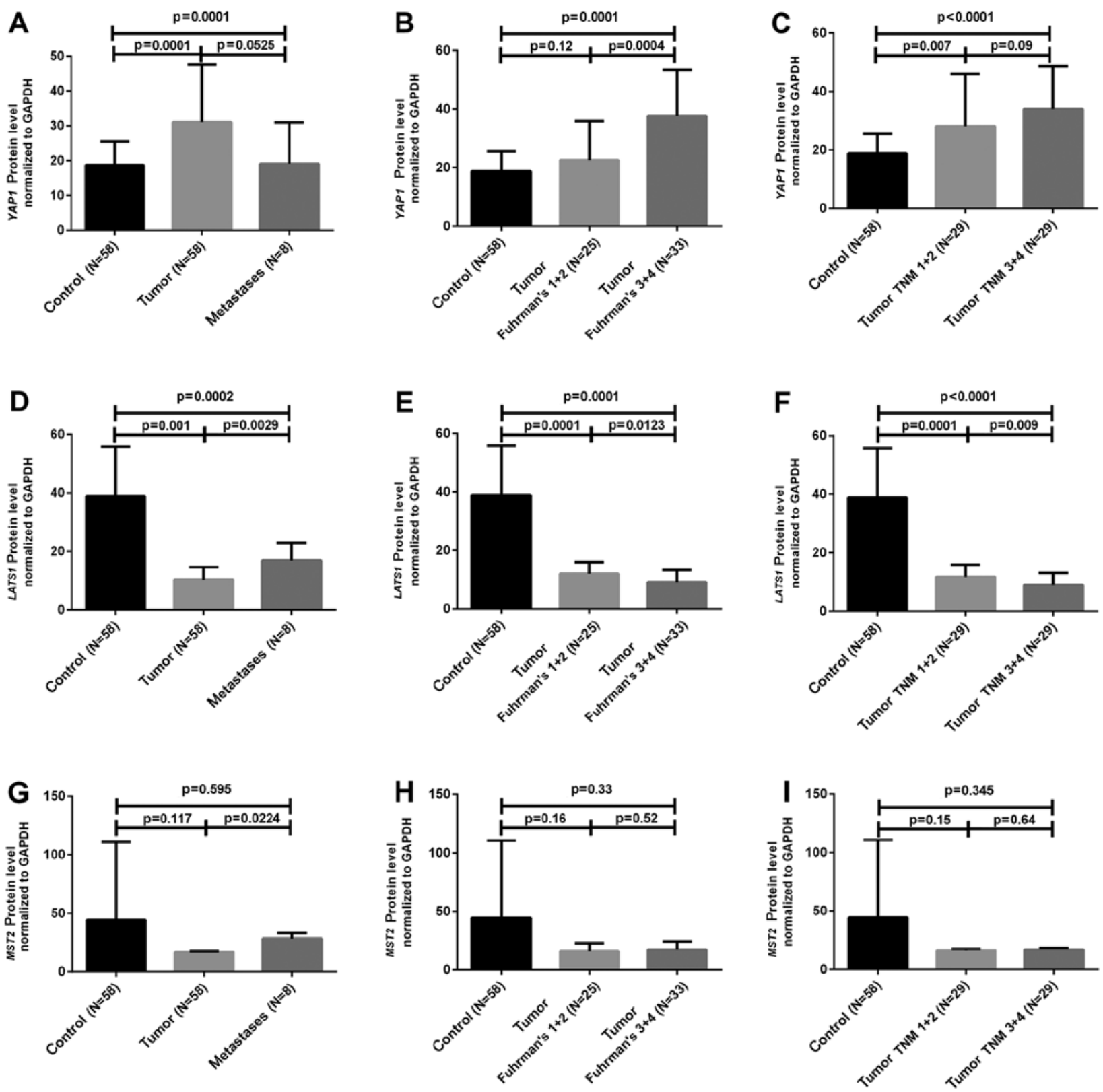

Figure 2. Analysis of YAP1, LATS1 and MST2 proteins in ccRCC by western blot analysis. Semi-quantitative analysis of YAP1 (A), LATS1 (D) and MST2 (G) in samples. Plots show protein expression in tumor samples related to Fuhrman's grading (B, E and H) and TNM (C, F and I). Bars and whiskers represent mean \pm SEM normalized to GAPDH level in each sample. P-values between groups (Mann-Whitney U test) are noted. LATS1, large tumor suppressor kinase 1; YAP1, Yes-associated protein 1.

of 86 tumor samples contained an increased YAPl mRNA level (Table I). The mRNA levels of LATS1 were $\sim 3$ and 25 times lower in the $\mathrm{T}$ and $\mathrm{M}$ samples $(\mathrm{p}<0.05)($ Fig. 1D) and lower LATS1 mRNA content was observed in 75/86 (87\%) tumor samples (Table I). On the contrary, the expression of MST2 at the mRNA level was decreased only in M samples, showing a statistically not significantly increased ratio in $43 / 86(50 \%) \mathrm{T}$ samples as compared to the level in the control tissue (Fig. 1G and Table I). The comparison of the clinicopathological data with mRNA levels revealed that poorly developed ccRCC tumors (Fuhrman's grades 3 and 4) were characterized by decreased LATSI and increased YAPI mRNA levels (Table I and Fig. 1B and E) as compared to the control samples. In addition, we found either lower LATSI mRNA level or higher YAPI mRNA ratio in tumor ccRCC cases which were diagnosed with local (N1-2) or distant metastasis (M1) as shown in Table I and Fig. 1C and F. No statistically significant relationships between MST2 mRNA ratios and clinical data were observed except for the higher content of MST2 transcript in samples obtained from larger tumors (Table I).

Expression of YAP1, LATS1 and MST2 proteins. The semi-quantification of the studied proteins normalized to GAPDH protein was performed in paired samples of $58 \mathrm{ccRCC}$ cases as well as in $8 \mathrm{M}$ cases. As presented in Fig. 2A and Table III, the YAP1 protein level was $\sim 2$ times higher in 47 $(81 \%)$ of the 58 analyzed T samples, whereas LATS1 protein ratio was $\sim 4$ times lower in $42(72 \%) \mathrm{T}$ samples when compared to the $\mathrm{C}$ samples (Fig. 2D). The relationship between 

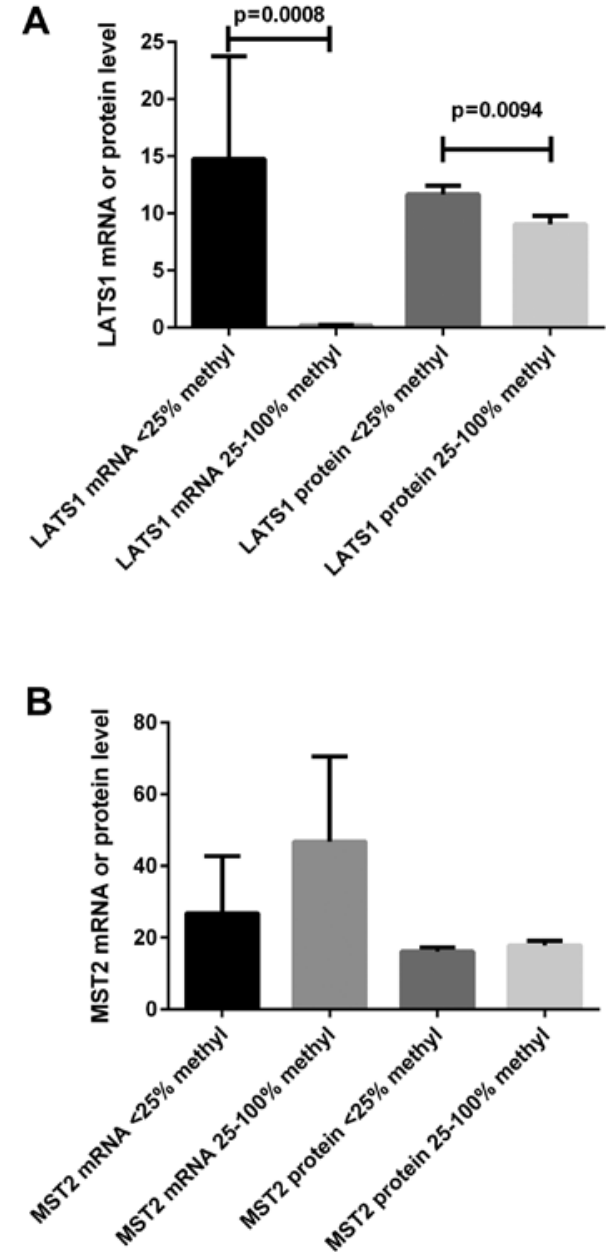

Figure 3. Quantitative comparison between LATS1 and MST2 mRNA and protein levels in tumor samples divided according to the methylation of LATS1 and MST2 gene promoters. qPCR and western blot results of either LATS1 (A) or MST2 (B) mRNA and protein levels in samples divided according to DNA methylation; $25 \%$ DNA methylation was treated as the threshold. Bars and whiskers represent mean \pm SEM of either mRNA normalized to GUSB1 mRNA level or protein normalized to GAPDH protein level in each sample. Mann-Whitney U test was applied: P-values $<0.05$ are noted. LATS1, large tumor suppressor kinase 1.

clinicopathological data and LATS1 and YAP1 protein expression was noted. Poorly developed (high Fuhrman's grades) T cases were characterized by increased YAP1 and decreased LATS1 protein ratios (Table III and Fig. 2B and E). The difference in protein expression of either LATS1 or YAP1 between non-metastatic vs. metastatic tumor ccRCC cases was observed (Table III and Fig. 2C and F). Semi-quantification of MST2 protein did not show any differences either between tumor and normal kidney samples or between cancer samples classified according to clinicopathological status (Table III an d Fig. 2G H and I).

LATS1 and MST2 promoter methylation status. Methylation analysis was carried out in 58 tumor and 10 control samples. According to the analysis of MD/UMD standards, the results of MS-HRM-qPCR were qualified into four grades: 1, 0-10\% methylation; $2,10-25 \% ; 3,25-50 \% ; 4,50-100 \%$. Based on the results of 10 control samples and our previous results (26), we set the value $>25 \%$ methylation as the hypermethylation status for either LATS1 or MST2 promoters. We found that LATS1

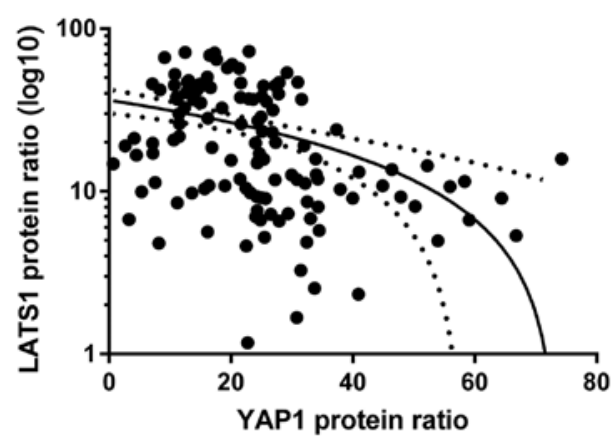

Figure 4. Correlation between LATS1 and YAP1 protein levels in all samples. The semi-quantitative results of protein assessment are presented as a plot; results for LATS1 protein are shown in $\log 10$ scale due to the high dispersion of data. Solid line represents linear regression curve with $95 \%$ confidence band (dots); rs=-0.51; $<<0.05$, Spearman's test. LATS1, large tumor suppressor kinase 1; YAP1, Yes-associated protein 1.

or MST2 hypermethylation was observed in $28(48 \%)$ or $22(38 \%)$ of 58 tumor ccRCC samples, respectively (Table III). The hypermethylation of LATS1 promoter was associated with higher Fuhrman's grades ( 3 and 4 vs. 1 and 2) as well as the presence of local and/or distant metastasis (Table III). Since the same T samples were analyzed for either LATS1 or MST2 methylation and mRNA and protein content, we ascertained whether the hypermethylation of the gene promoter region was associated with its mRNA/protein content. As shown in Fig. 3, the mRNA and protein expression of LATS1 gene was related to the hypermethylation status of this gene; such observation was not proven for the MST2 gene.

Relationships between LATS1, MST2 and YAP1 proteins. We checked possible correlations between mRNA-mRNA, mRNA-protein, protein-mRNA and protein-protein levels of LATS1-YAP1, LATS1-MST2 and MST2-YAP1. We found a negative correlation between LATS1 protein and YAP1 protein levels when all paired samples of 58 patients were taken into consideration (rs=-0.51; $<<0.05$, Spearman's test; Fig. 4).

Association between molecular findings and clinicopathological parameters and patient outcome. As presented in Figs. 5A and B and 6A and B, OS as well as PFS were strongly associated with a higher TNM and Fuhrman's grading in the patients. The molecular data revealed that increased YAP1 expression levels either at the mRNA or protein levels as well as the hypermethylation of LATS1 promoter were related to both PFS and OS (Figs. 5C-E and 6C-E). The increased level of MST2 mRNA was associated with shorter OS (Fig. 5F).

Cox proportional hazard model with multivariate analyses revealed that the YAPI mRNA level was an independent predictor of OS in ccRCC patients when assessed by Fuhrman's histological grade (Table IV). There was no association between molecular data and hazard ratio when the PFS rate was checked (Table V).

\section{Discussion}

The Hippo pathway is an important regulator of cell proliferation, tissue homeostasis, organ size and stem cell func- 


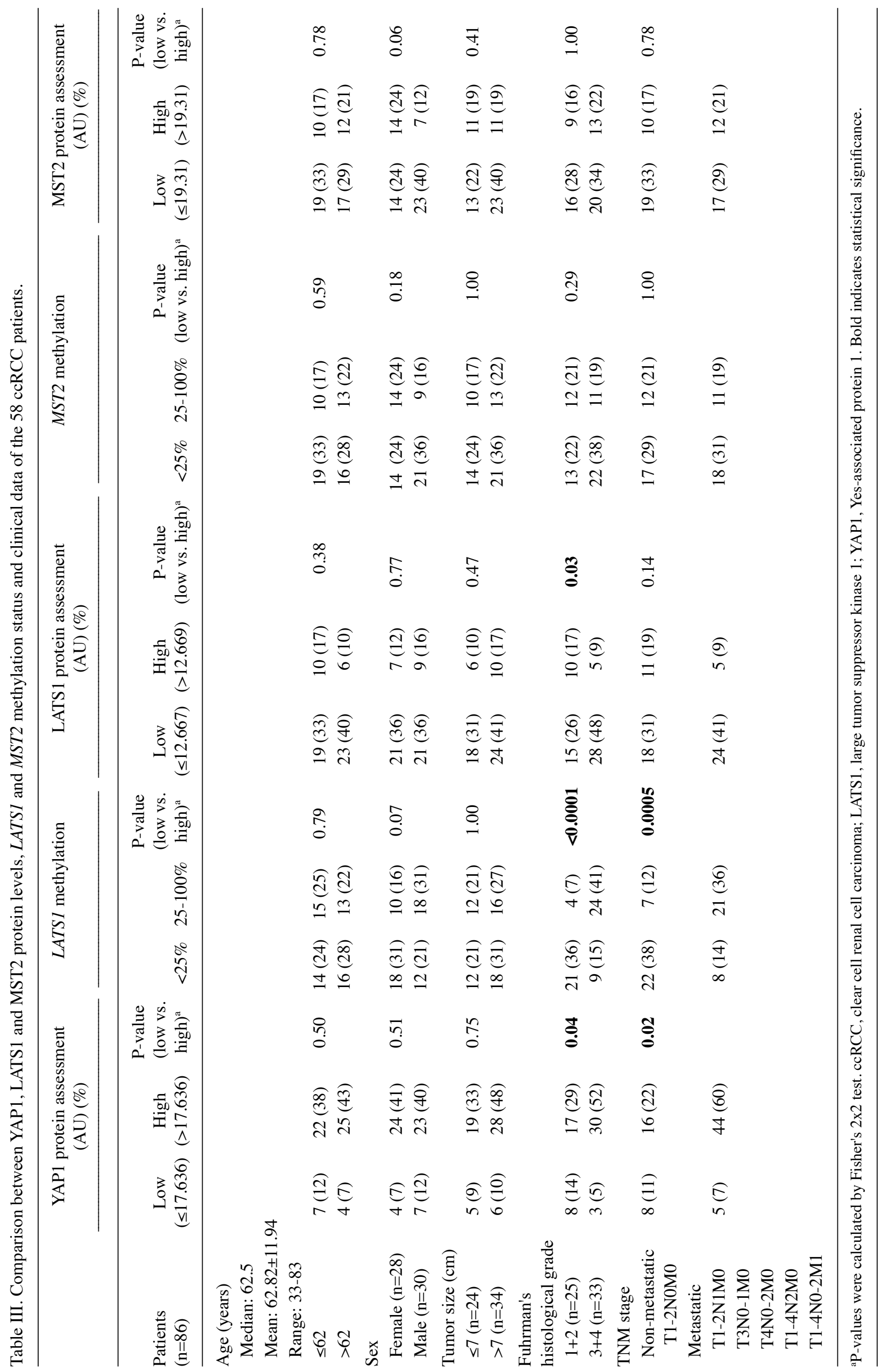



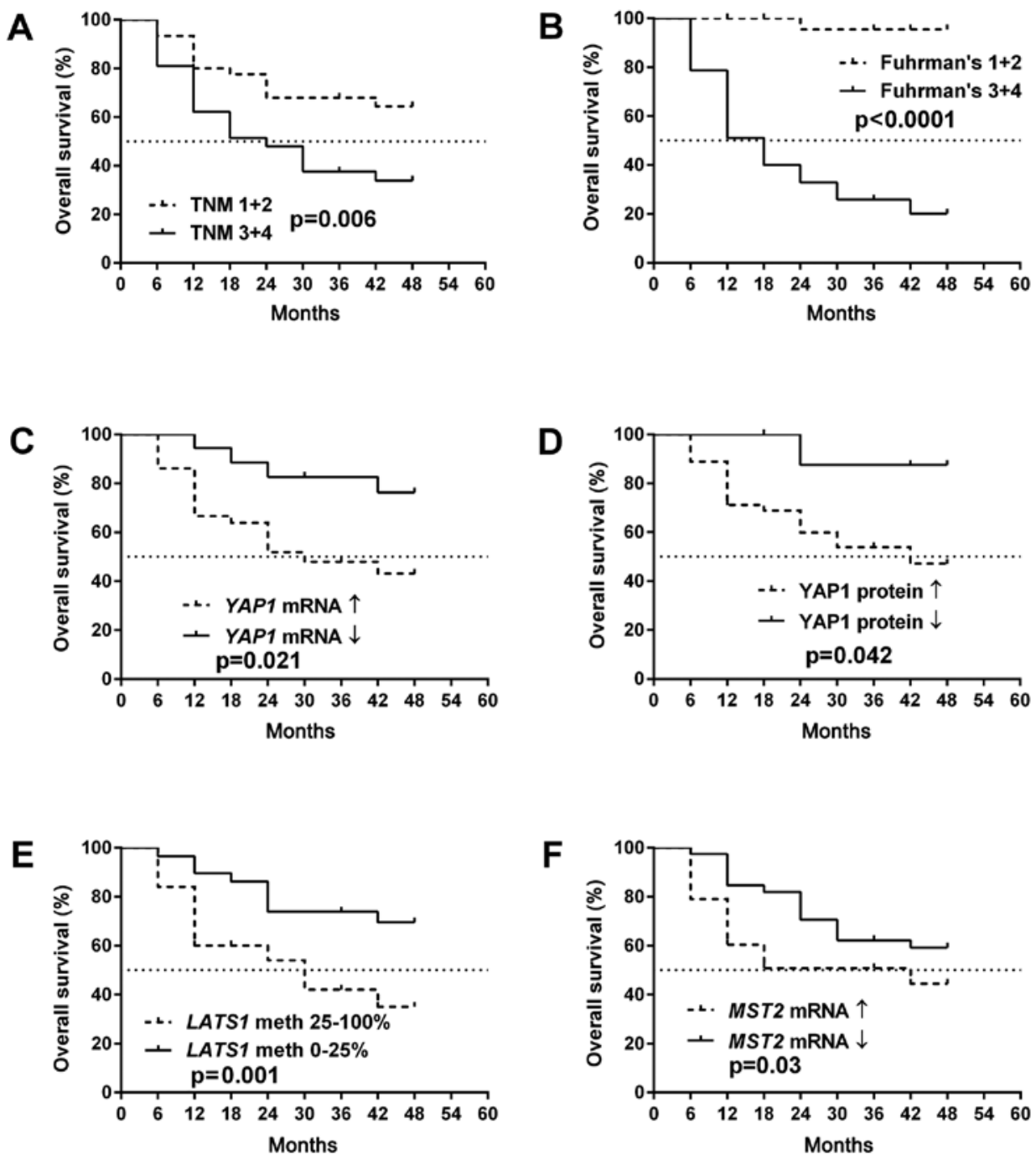

Figure 5. Kaplan-Meier's overall survival analysis of ccRCC patients related to clinicopathological and molecular data. Overall survival plots for 86 (A-C and F) or 58 (D and E) ccRCC patients. ccRCC, clear cell renal cell carcinoma. LATS1, large tumor suppressor kinase 1; YAP1, Yes-associated protein 1.
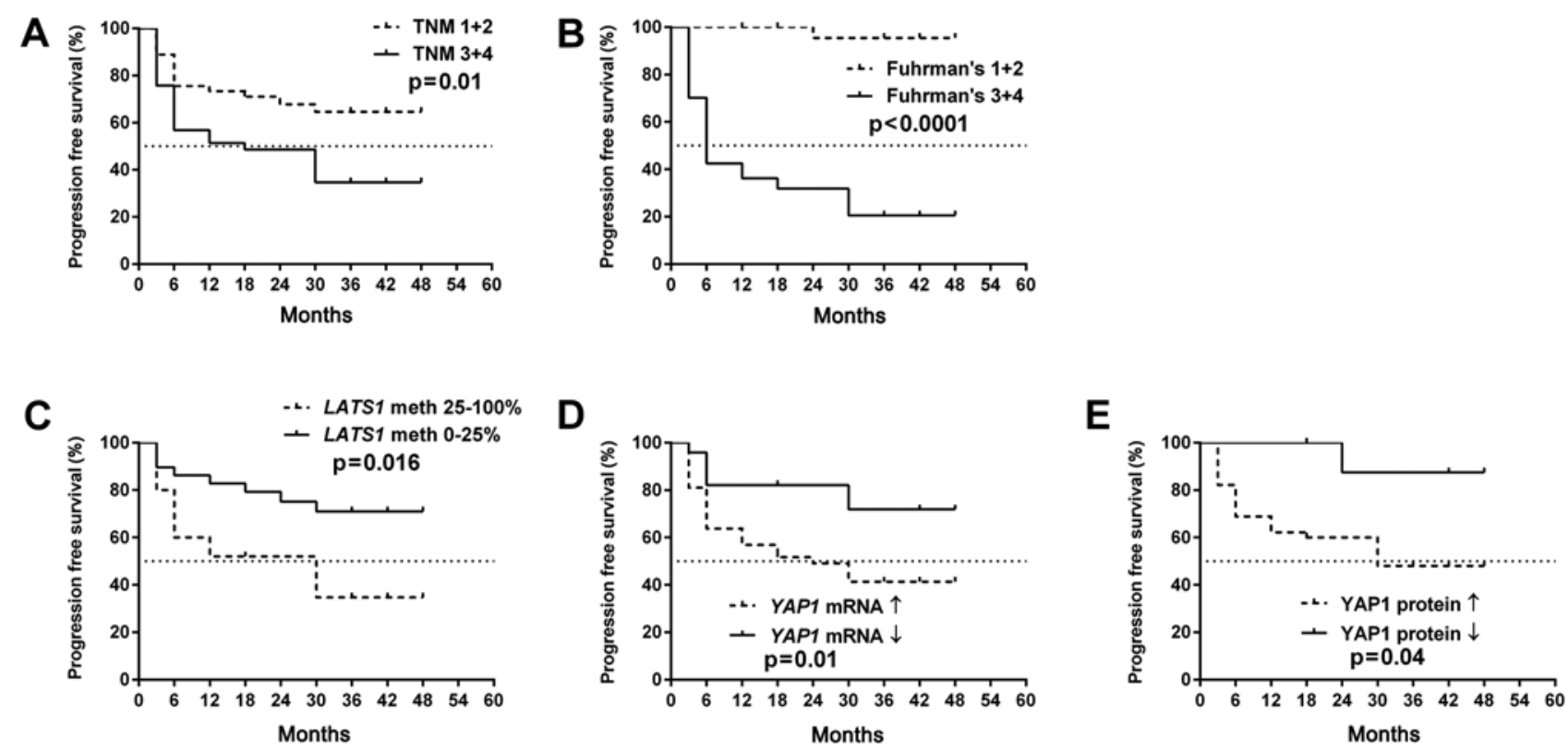

Figure 6. Kaplan-Meier's progression-free survival analysis of ccRCC patients related to clinicopathological and molecular data. Progression-free survival plots for 86 (A, B and D) or 58 (C and E) ccRCC patients. ccRCC, clear cell renal cell carcinoma. LATS1, large tumor suppressor kinase 1; YAP1, Yesassociated protein 1 . 
Table IV. Univariable and multivariable Cox regression analysis of the overall survival rate of the ccRCC patients.

\begin{tabular}{|c|c|c|c|c|}
\hline \multirow[b]{2}{*}{ Parameters } & \multicolumn{2}{|c|}{ Univariable analysis } & \multicolumn{2}{|c|}{ Multivariable analysis } \\
\hline & P-value & $\mathrm{HR}(95 \% \mathrm{CI})$ & P-value & HR $(95 \% \mathrm{CI})$ \\
\hline \multicolumn{5}{|l|}{ Sex } \\
\hline Female vs. Male & 0.064 & $2.28(0.95-5.46)$ & & \\
\hline \multicolumn{5}{|l|}{ Age (years) } \\
\hline$>62$ vs. $\leq 62$ & 0.56 & $0.78(0.34-1.786)$ & & \\
\hline \multicolumn{5}{|l|}{ Tumor size (cm) } \\
\hline$>7$ vs. $\leq 7$ & 0.29 & $0.64(0.285-1.47)$ & & \\
\hline \multicolumn{5}{|l|}{ Tumor grade } \\
\hline $\mathrm{T} 3+4$ vs. $\mathrm{T} 1+2$ & 0.001 & $4.72(1.85-12.06)$ & 0.91 & $0.93(0.28-3.15)$ \\
\hline \multicolumn{5}{|l|}{ Histological grade } \\
\hline $\mathrm{F} 3+4$ vs. $\mathrm{F} 1+2$ & 0.0005 & $8.61(2.54-29.18)$ & 0.019 & $6.04(1.34-27.26)$ \\
\hline \multicolumn{5}{|l|}{ LATS1 mRNA levels } \\
\hline$\downarrow(\leq 1.982)$ vs. $\uparrow(>1.982)$ & 0.58 & $1.35(0.46-3.99)$ & & \\
\hline \multicolumn{5}{|l|}{ LATS1 methylation } \\
\hline$\uparrow(>25 \%)$ vs. $\downarrow(\leq 25 \%)$ & 0.01 & $3.06(1.29-7.29)$ & 0.52 & $1.35(0.52-3.51)$ \\
\hline \multicolumn{5}{|l|}{ LATS1 protein levels } \\
\hline$\downarrow(\leq 12.669)$ vs. $\uparrow(>12.669)$ & 0.33 & $0.58(0.19-1.72)$ & & \\
\hline \multicolumn{5}{|l|}{ YAP1 mRNA levels } \\
\hline$\uparrow(>0.328)$ vs. $\downarrow(\leq 0.328)$ & 0.01 & $4.87(1.43-16.52)$ & 0.036 & $4.03(0.96-16.79)$ \\
\hline \multicolumn{5}{|l|}{ YAP1 protein levels } \\
\hline$\uparrow(>17.363)$ vs. $\downarrow(\leq 17.363)$ & 0.047 & $6.11(0.82-45.48)$ & 0.67 & $1.60(0.17-14.43)$ \\
\hline \multicolumn{5}{|l|}{ MST2 mRNA levels } \\
\hline$\downarrow(\leq 0.539)$ vs. $\uparrow(>0.539)$ & 0.72 & $1.16(0.49-2.71)$ & & \\
\hline \multicolumn{5}{|l|}{ MST2 methylation } \\
\hline$\uparrow(>25 \%)$ vs. $\downarrow(\leq 25 \%)$ & 0.52 & $0.75(0.32-1.78)$ & & \\
\hline \multicolumn{5}{|l|}{ MST2 protein levels } \\
\hline$\downarrow(\leq 10.09)$ vs. $\uparrow(>10.09)$ & 0.82 & $0.91(0.39-2.11)$ & & \\
\hline
\end{tabular}

ccRCC, clear cell renal cell carcinoma; HR, hazard ratio; LATS1, large tumor suppressor kinase 1; YAP1, Yes-associated protein 1; CI, confidence interval. Bold indicates statistical significance.

tions (6). Its deregulation is frequently observed in many types of malignancies, suggesting that alterations of this signaling are connected with cancer progression and patient survival $(7-9,21,33,34)$. The core components of this pathway include MST1/2, SAV1, LATS1/2 and MOB1 proteins $(10,12,15)$. When the Hippo signaling is active, LATS1/2 kinases phosphorylate two major downstream effectors, YAP1 or its paralog, TAZ, resulting in their ubiquitination and proteolytic degradation $(35,36)$. In contrast, deregulation of the pathway components, the consequent Hippo silencing, increases the YAP1 protein level in the cell as well as augments the nuclear localization of YAP1 (37). In turn, YAP1 nuclear accumulation triggers the upregulation of target genes (e.g., CTFG and CYR61), which are associated with processes such as cell migration, proliferation and angiogenesis (37).

The recent results of in vitro studies show that the inhibition of LATS1 kinase is strongly connected with the upregulation of YAP1 resulting in the increased metastatic potential of cancer cells $(35,38)$. Mei et al showed that direct interaction between small ubiquitin-like modifier (SUMO) and LATS1 protein in L02 (normal human hepatic) and HepG2 (hepatocellular carcinoma) cells resulted in the attenuation of LATS1 kinase activity and inhibition of the Hippo pathway. As a consequence, the levels of YAP1, CTFG and CYR61 proteins were increased in SUMOtylated-LATS1 cells (35). Our results based on clinical samples of ccRCC showed a direct association between the presence of LATS1 and YAP1 in kidney tissues; a decreased LATS1 protein level was correlated with increased ratio of YAP1 protein in both tumor and matched normal kidney tissue samples. Another recent study on LATS1-YAP1 interaction in cancer (38) was performed in MDA-MB-231 and MCF7 breast cancer cell lines. Nokin et al found that methylglyoxal, a glycolysis side-product, indirectly targets inactivation of LATS1 in cells. As a result, increased levels of YAP1 protein and its co-effectors were observed which corresponded with the increased metastatic potential of cancer cells in a mouse xenograft model (38). The results of our study indicate that the decreased expression of LATS1 
Table V. Univariable and multivariable Cox regression analysis of progression-free survival rate of ccRCC patients.

\begin{tabular}{|c|c|c|c|c|}
\hline \multirow[b]{2}{*}{ Parameters } & \multicolumn{2}{|c|}{ Univariable analysis } & \multicolumn{2}{|c|}{ Multivariable analysis } \\
\hline & P-value & HR (95\% CI) & P-value & $\mathrm{HR}(95 \% \mathrm{CI})$ \\
\hline \multicolumn{5}{|l|}{ Sex } \\
\hline Female vs. Male & 0.11 & $3.12(1.29-7.59)$ & & \\
\hline \multicolumn{5}{|l|}{ Age (years) } \\
\hline$>62$ vs. $\leq 62$ & 0.44 & $0.78(0.34-1.786)$ & & \\
\hline \multicolumn{5}{|l|}{ Tumor size $(\mathrm{cm})$} \\
\hline$>7$ vs. $\leq 7$ & 0.43 & $0.72(0.32-1.62)$ & & \\
\hline \multicolumn{5}{|l|}{ Tumor grade } \\
\hline $\mathrm{T} 3+4$ vs. $\mathrm{T} 1+2$ & 0.002 & $3.84(1.58-9.31)$ & 0.77 & $0.84(0.26-2.66)$ \\
\hline \multicolumn{5}{|l|}{ Histological grade } \\
\hline $\mathrm{F} 3+4$ vs. F1+2 & 0.0002 & $15.01(3.51-64.19)$ & 0.001 & $13.68(2.73-68.34)$ \\
\hline \multicolumn{5}{|l|}{ LATS1 mRNA levels } \\
\hline$\downarrow(\leq 1.982)$ vs. $\uparrow(>1.982)$ & 0.54 & $0.61(0.12-2.95)$ & & \\
\hline \multicolumn{5}{|l|}{ LATS1 methylation } \\
\hline$\uparrow(>25 \%)$ vs. $\downarrow(\leq 25 \%)$ & 0.65 & $1.27(0.43-3.77)$ & & \\
\hline \multicolumn{5}{|l|}{ LATS1 protein levels } \\
\hline$\downarrow(\leq 12.669)$ vs. $\uparrow(>12.669)$ & 0.49 & $0.70(0.26-1.89)$ & & \\
\hline \multicolumn{5}{|l|}{ YAP1 mRNA levels } \\
\hline$\uparrow(>0.328)$ vs. $\downarrow(\leq 0.328)$ & 0.008 & $2.39(0.88-6.45)$ & 0.09 & $1.84(0.45-6.23)$ \\
\hline \multicolumn{5}{|l|}{ YAP1 protein levels } \\
\hline$\uparrow(>17.363)$ vs. $\downarrow(\leq 17.363)$ & 0.007 & $6.21(0.83-46.07)$ & 0.12 & $1.72(0.19-14.91)$ \\
\hline \multicolumn{5}{|l|}{ MST2 mRNA levels } \\
\hline$\downarrow(\leq 0.539)$ vs. $\uparrow(>0.539)$ & 0.61 & $1.23(0.54-2.79)$ & & \\
\hline \multicolumn{5}{|l|}{ MST2 methylation } \\
\hline$\uparrow(>25 \%)$ vs. $\downarrow(\leq 25 \%)$ & 0.18 & $0.55(0.22-1.32)$ & & \\
\hline \multicolumn{5}{|l|}{ MST2 protein levels } \\
\hline$\downarrow(\leq 10.09)$ vs. $\uparrow(>10.09)$ & 0.52 & $0.76(0.34-1.72)$ & & \\
\hline
\end{tabular}

ccRCC, clear-cell renal cell carcinoma; HR, hazard ratio; LATS1, large tumor suppressor kinase 1; YAP1, Yes-associated protein 1; CI, confidence interval. Bold indicates statistical significance.

and increased YAP1 either at the mRNA or protein levels are highly associated with renal cancer progression.

Our data corroborate the findings of Chen et al (39) in an RCC cell line (786-O) as well as in tissue samples. In paired tumor and normal kidney samples of $30 \mathrm{ccRCC}$ patients they observed decreased LATS1 mRNA and protein levels in tumor samples; ccRCC progression was associated with lower LATS1 content (39). Our data obtained on a much larger group of ccRCC patients extend these observations suggestive of the roles of LATS1 and YAP1 in ccRCC development since we found that the patients with deregulated LATS1 or YAP1 mRNA and protein levels share poorer clinical outcome. Thus, our and Chen et al (39) findings suggest that measurements of YAPl mRNA content in ccRCC tumor samples could serve as a potential survival marker together with high Fuhrman's grades. In contrast to a previous study (37) we used quantitative techniques (qPCR vs. RT-PCR and MS-HRM-qPCR vs. bisulfide sequencing PCR) to assess a much larger group of
ccRCC patients (86 vs. 30). Although we did not focus on the expression of Hippo pathway components in renal cancer cell lines, Chen et al showed in 786-O and HEK293 kidney cell lines that the decreased expression of LATS1 was associated with promoter hypermethylation (39) which was found by us in ccRCC clinical samples. Moreover, we observed that LATS1 hypermethylation in tumor samples was characteristic of ccRCC patients with earlier occurrence of either metastasis or death. Chen et al also found that the controlled decrease in LATS1 protein level resulted in an increased YAP1 protein level. Furthermore, they observed that overexpression of LATS1 downregulated the YAP1 protein level, inhibited cell proliferation, induced cell apoptosis and cell cycle arrest in 786-O cells (39). LATS1 downregulation and its contribution to cancer progression has been observed in other malignances such as glioma (40), nosopharyngeal carcinoma (41), astrocytoma (42), non-small cell lung cancer (18), breast cancer (16), colorectal cancer (17) and renal carcinoma (39). Additionally, 
association between LATS1 hypermethylation and tumor progression has been noted in lung cancer (43), schwannomas (44), oral squamous cell carcinoma (45), colorectal cancer (17) and astrocytoma (42), however, the authors did not observe the influence of LATS1 methylation status on patient outcome. Therefore, we believe that our observations may promote studies of LATS1 gene/protein expression to assess the impact on ccRCC progression and prognosis.

Our results suggest that the second core part of Hippo signaling, MST2 protein, is neither involved in ccRCC progression nor in YAP1 regulation. Although MST1/2 kinases have been acknowledged as tumor-suppressor proteins since loss of function of MST1/2 was observed in prostate (46) and breast cancer (47), and a decreased MST1 mRNA level was associated with node metastasis in colorectal cancer (48), however, in hepatocellular carcinoma HepG2 cells increased MST1/2 levels were reported (49). Decreased MST1 expression was associated with promoter methylation of this gene in soft tissue sarcomas (50). Since we did not find an association between $M S T 1$ promoter methylation and gene expression, we suggest that such a regulation of MSTl gene expression does not occur in ccRCC. MST1 protein is the upstream regulator of YAP1 protein $(10,12,13,15,48,51,52)$, therefore the lack of an MST1/YAP1 association as observed by us in ccRCC should be discussed. The relationship between MST1/2 protein and YAP1 level in intestinal epithelium was observed by Zhou et al during an in vivo study (53). Their study using an Mst1/2-deficient mouse model showed that MST1 and MST2 proteins are crucial in the regulation of the Yap1 protein level in normal colonic epithelium (53). On the contrary, they found that the antiproliferative role of MST1 or MST2 was overcome in colon cancer by the abundance of Yap1 protein (53). Such an observation is in line with our results, since we did not find alterations in the expression of MST1 mRNA or protein levels in the studied samples of ccRCC. Another in vivo study using mouse models showed different results in regards to the Mst2/ Yap1 association in cancer development (19). Zhou et al found that tumorigenesis of hepatocellular carcinoma was associated with loss of Mst2 and a decreased level of phosphorylated Yap1 protein (19). Such an observation could be contrary to our results, however, they observed that the deregulation of Mst1/2 protein did not change the level of Lats1/2 proteins. Based on that, we suppose that such independent regulation of MST2 and LATS1 may occur in ccRCC. However, such a conclusion should be supported by further studies. Moreover, since our study is the first to use complex MST2 quantification in ccRCC, we propose that lack of contribution of this gene in renal cancer progression must be confirmed by independent studies.

The most significant observation revealed in our study was, in our opinion, the possibility of YAPl mRNA measurement as a potential prognostic factor in ccRCC. Our previous study showed a similar correlation between Hippo upstream regulator, RASSF1A gene, and patient outcome (26). Therefore, in this study we aimed to assess the possible role of YAP1 in ccRCC. Although our report is not the first study of YAP1 expression in ccRCC since Cao et al published a similar study in 2014 (54), there are some significant differences: a larger group of patients ( 86 vs. 30 persons), study on metastasized samples, modern quantitative techniques (qPCR vs. classical
PCR) and survival data. Despite the mentioned differences, Cao et al obtained comparable results since the increased YAP1 protein level was associated with higher Fuhrman's and clinical stages (54). They also performed in vitro studies on 786-O and HEK293 kidney cells and found that knockdown of YAPl inhibited expression of the TEADl gene as well as suppressed cell proliferation (54). Most studies on the role of YAP1 in other cancer types such as RCC (39), oral squamous cell carcinoma (55), ovarian cancer (56), head and neck cancer (57), colorectal cancer (58), melanoma (59), lung (18) and breast cancer (23), revealed an association between YAP1 overexpression (mostly at the protein level) and tumor progression. Furthermore, we found that increased YAP1 levels of either mRNA or protein in tumor samples were associated with poorer patient outcome (survival and occurrence of metastasis). Other authors found a similar correlation between higher YAP1 levels and patient outcome in esophageal cancer (60), gastric adenocarcinoma (61) and papillary thyroid cancer (62).

Another important aspect is the mechanism of YAPI mRNA regulation. Notably, we observed that only ccRCC patients with increased YAPI mRNA levels in tumor samples were characterized by a higher risk of death (Cox test). Recent data indicate that some microRNA molecules directly regulate the YAP1 mRNA level. Pan et al found that miR-509-3p targeted YAP1 mRNA in a large group (293 cases from TCGA cohort) of ovarian cancer (63). Moreover, miR-138 was found to be a strong suppressor of YAP1 mRNA in oral squamous cell carcinoma (64) and in non-small cell lung cancer (65). The reported associations between decreased levels of either miR-509-3p or miR-138 in the studied types of cancer and poorer patient outcome (63-65), consolidating the influence of YAP1 in tumor progression. In fact, the contribution of YAP1 protein in tumor progression is so important that it was acknowledged as a pivotal molecular target in modern cancer treatment $(5,34,38,51,52,66,67)$. Some authors found an association between YAP1 overexpression and chemoresistance of cancer cells, e.g., in head and neck cancer cases resistant to cetuximab (57), resistance to RAF- and MEK-targeted therapy (33), 5-FU chemotherapy-resistant colon cancer (68) and osteosarcoma resistance (69).

In conclusion, we suggest that dysregulation of LATS1 and $Y A P 1$ levels, but not MST2, is associated with ccRCC progression and patient survival. We propose that the assessment of YAPl mRNA levels in paired tumor-normal kidney tissue samples could serve as a new prognostic factor in ccRCC.

\section{Acknowledgements}

The authors wish to thank Dr Marcin Stanislawowski and Dr Tomasz Slebioda from the Department of Histology for the laboratory support. The study was supported by National Science Centre (Poland) grant 2012/05/B/NZ4/02735 and ST-12 internal funds of the Medical University of Gdansk, Poland.

\section{References}

1. Novara G, Martignoni G, Artibani W and Ficarra V: Grading systems in renal cell carcinoma. J Urol 177: 430-436, 2007. 
2. Massari F, Bria E, Maines F, Milella M, Giannarelli D, Cognetti F, Pappagallo G, Tortora G and Porta C: Adjuvant treatment for resected renal cell carcinoma: Are all strategies equally negative? Potential implications for trial design with targeted agents. Clin Genitourin Cancer 11: 471-476, 2013.

3. Keizman D, Rouvinov K, Sella A, Gottfried M, Maimon N, Kim JJ, Eisenberger MA, Sinibaldi V, Peer A, Carducci MA, et al: Is there a 'Trial Effect' on outcome of patients with metastatic renal cell carcinoma treated with sunitinib? Cancer Res Treat 48: 281-287, 2016

4. van der Mijn JC, Mier JW, Broxterman HJ and Verheul HM: Predictive biomarkers in renal cell cancer: Insights in drug resistance mechanisms. Drug Resist Updat 17: 77-88, 2014.

5. Zhao B, Lei QY and Guan KL: The Hippo-YAP pathway: New connections between regulation of organ size and cancer. Curr Opin Cell Biol 20: 638-646, 2008.

6. Zhao B, Li L, Lei Q and Guan KL: The Hippo-YAP pathway in organ size control and tumorigenesis: An updated version. Genes Dev 24: 862-874, 2010.

7. Liu H, Jiang D, Chi F and Zhao B: The Hippo pathway regulates stem cell proliferation, self-renewal, and differentiation. Protein Cell 3: 291-304, 2012.

8. Harvey KF, Zhang X and Thomas DM: The Hippo pathway and human cancer. Nat Rev Cancer 13: 246-257, 2013.

9. Zhao B, Tumaneng K and Guan KL: The Hippo pathway in organ size control, tissue regeneration and stem cell self-renewal. Nat Cell Biol 13: 877-883, 2011.

10. Halder G and Johnson RL: Hippo signaling: Growth control and beyond. Development 138: 9-22, 2011.

11. Moya IM and Halder G: The Hippo pathway in cellular reprogramming and regeneration of different organs. Curr Opin Cell Biol 43: 62-68, 2016.

12. Wierzbicki PM and Rybarczyk A: The Hippo pathway in colorectal cancer. Folia Histochem Cytobiol 53: 105-119, 2015.

13. Janse van Rensburg HJ and Yang X: The roles of the Hippo pathway in cancer metastasis. Cell Signal 28: 1761-1772, 2016.

14. Johnson R and Halder G: The two faces of Hippo: Targeting the Hippo pathway for regenerative medicine and cancer treatment Nat Rev Drug Discov 13: 63-79, 2014.

15. Cai J, Zhang N, Zheng Y, de Wilde RF, Maitra A and Pan D: The Hippo signaling pathway restricts the oncogenic potential of an intestinal regeneration program. Genes Dev 24: 2383-2388, 2010.

16. Morinaga N, Shitara Y, Yanagita Y, Koida T, Kimura M, Asao T, Kimijima I, Takenoshita S, Hirota T, Saya H, et al: Molecular analysis of the h-warts/LATS1 gene in human breast cancer. Int J Oncol 17: 1125-1129, 2000.

17. Wierzbicki PM, Adrych K, Kartanowicz D, Stanislawowski M, Kowalczyk A, Godlewski J, Skwierz-Bogdanska I, Celinski K, Gach T, Kulig J, et al: Underexpression of LATS1 TSG in colorectal cancer is associated with promoter hypermethylation. World J Gastroenterol 19: 4363-4373, 2013.

18. Lin XY, Zhang XP, Wu JH, Qiu XS and Wang EH: Expression of LATS1 contributes to good prognosis and can negatively regulate YAP oncoprotein in non-small-cell lung cancer. Tumour Biol 35: 6435-6443, 2014.

19. Zhou D, Conrad C, Xia F, Park JS, Payer B, Yin Y, Lauwers GY, Thasler W, Lee JT, Avruch J, et al: Mst1 and Mst2 maintain hepatocyte quiescence and suppress hepatocellular carcinoma development through inactivation of the Yap1 oncogene. Cancer Cell 16: 425-438, 2009.

20. Miyanaga A, Masuda M, Tsuta K, Kawasaki K, Nakamura Y, Sakuma T, Asamura H, Gemma A and Yamada T: Hippo pathway gene mutations in malignant mesothelioma: Revealed by RNA and targeted exon sequencing. J Thorac Oncol 10: $844-851,2015$

21. Bora-Singhal N, Nguyen J, Schaal C, Perumal D, Singh S, Coppola D and Chellappan S: YAP1 regulates OCT4 activity and SOX2 expression to facilitate self-renewal and vascular mimicry of stem-like cells. Stem Cells 33: 1705-1718, 2015.

22. Machado-Neto JA, Lazarini M, Favaro P, Franchi GC Jr, Nowill AE, Saad ST and Traina F: ANKHD1, a novel component of the Hippo signaling pathway, promotes YAP1 activation and cell cycle progression in prostate cancer cells. Exp Cell Res 324 $137-145,2014$

23. Vlug EJ, van de Ven RA, Vermeulen JF, Bult P, van Diest PJ and Derksen PW: Nuclear localization of the transcriptional coactivator YAP is associated with invasive lobular breast cancer. Cell Oncol (Dordr) 36: 375-384, 2013.
24. Li M, Lu J, Zhang F, Li H, Zhang B, Wu X, Tan Z, Zhang L, Gao G, $\mathrm{Mu} \mathrm{J}$, et al: Yes-associated protein 1 (YAP1) promotes human gallbladder tumor growth via activation of the AXL/MAPK pathway. Cancer Lett 355: 201-209, 2014.

25. Liu YC and Wang YZ: Role of Yes-associated protein 1 in gliomas: Pathologic and therapeutic aspects. Tumour Biol 36: 2223-2227, 2015.

26. Klacz J, Wierzbicki PM, Wronska A, Rybarczyk A, Stanislawowski M, Slebioda T, Olejniczak A, Matuszewski M and Kmiec Z: Decreased expression of RASSF1A tumor suppressor gene is associated with worse prognosis in clear cell renal cell carcinoma. Int J Oncol 48: 55-66, 2016.

27. Wierzbicki PM, Klacz J, Rybarczyk A, Slebioda T, Stanislawowski M, Wronska A, Kowalczyk A, Matuszewski M and Kmiec Z: Identification of a suitable qPCR reference gene in metastatic clear cell renal cell carcinoma. Tumour Biol 35: 12473-12487, 2014.

28. Schmittgen TD and Livak KJ: Analyzing real-time PCR data by the comparative C(T) method. Nat Protoc 3: 1101-1108, 2008

29. Wojdacz TK and Dobrovic A: Methylation-sensitive high resolution melting (MS-HRM): A new approach for sensitive and high-throughput assessment of methylation. Nucleic Acids Res 35: e41, 2007.

30. Avădănei ER, Wierzbicki PM, Giuşcă SE, Grigoraş A, Amălinei C and Căruntu ID: Macrophage profile in primary versus secondary liver tumors. Folia Histochem Cytobiol 52: 112-123, 2014.

31. Sobin LH, Gospodarowicz MK, Wittekind $C$ and International Union against Cancer: TNM classification of malignant tumours. Wiley-Blackwell, Chichester, West Sussex, UK; Hoboken, NJ, 2010.

32. Delahunt B, Sika-Paotonu D, Bethwaite PB, William Jordan T, Magi-Galluzzi C, Zhou M, Samaratunga $\mathrm{H}$ and Srigley JR: Grading of clear cell renal cell carcinoma should be based on nucleolar prominence. Am J Surg Pathol 35: 1134-1139, 2011.

33. Lin L, Sabnis AJ, Chan E, Olivas V, Cade L, Pazarentzos E, Asthana S, Neel D, Yan JJ, Lu X, et al: The Hippo effector YAP promotes resistance to RAF- and MEK-targeted cancer therapies. Nat Genet 47: 250-256, 2015.

34. Zhang L, Yang S, Chen X, Stauffer S, Yu F, Lele SM, Fu K, Datta K, Palermo N, Chen Y, et al: The hippo pathway effector YAP regulates motility, invasion, and castration-resistant growth of prostate cancer cells. Mol Cell Biol 35: 1350-1362, 2015.

35. Mei L, Yuan L, Shi W, Fan S, Tang C, Fan X, Yang W, Qian Y, Hussain $\mathrm{M}$ and $\mathrm{Wu} \mathrm{X}$ : SUMOylation of large tumor suppressor 1 at Lys751 attenuates its kinase activity and tumor-suppressor functions. Cancer Lett 386: 1-11, 2017.

36. Saucedo LJ and Edgar BA: Filling out the Hippo pathway. Nat Rev Mol Cell Biol 8: 613-621, 2007.

37. Yu FX, Zhao B and Guan KL: Hippo pathway in organ size control, tissue homeostasis, and cancer. Cell 163: 811-828, 2015.

38. Nokin MJ, Durieux F, Peixoto P, Chiavarina B, Peulen O, Blomme A, Turtoi A, Costanza B, Smargiasso N, Baiwir D, et al: Methylglyoxal, a glycolysis side-product, induces Hsp90 glycation and YAP-mediated tumor growth and metastasis. eLife 5: 5, 2016.

39. Chen KH, He J, Wang DL, Cao JJ, Li MC, Zhao XM, Sheng X, Li WB and Liu WJ: Methylation associated inactivation of LATS1 and its effect on demethylation or overexpression on YAP and cell biological function in human renal cell carcinoma. Int J Oncol 45: 2511-2521, 2014.

40. Zhang H, Geng D, Gao J, Qi Y, Shi Y, Wang Y, Jiang Y, Zhang Y, Fu J, Dong Y, et al: Expression and significance of Hippo/YAP signaling in glioma progression. Tumour Biol 37: 15665-15676, 2016.

41. He J, Tang F, Liu L, Chen L, Li J, Ou D, Zhang L, Li Z, Feng D, $\mathrm{Li} \mathrm{W}$, et al: Positive regulation of TAZ expression by EBV-LMP1 contributes to cell proliferation and epithelial-mesenchymal transition in nasopharyngeal carcinoma. Oncotarget: Dec 2, 2016 (Epub ahead of print). doi.org/10.18632/oncotarget.13775.

42. Jiang Z, Li X, Hu J, Zhou W, Jiang Y, Li G and Lu D: Promoter hypermethylation-mediated down-regulation of LATS1 and LATS2 in human astrocytoma. Neurosci Res 56: 450-458, 2006.

43. Sasaki H, Hikosaka Y, Kawano O, Yano M and Fujii Y: Hypermethylation of the large tumor suppressor genes in Japanese lung cancer. Oncol Lett 1: 303-307, 2010.

44. Oh JE, Ohta T, Satomi K, Foll M, Durand G, McKay J, Le Calvez-Kelm F, Mittelbronn M, Brokinkel B, Paulus W, et al: Alterations in the NF2/LATS1/LATS2/YAP pathway in schwannomas. J Neuropathol Exp Neurol 74: 952-959, 2015. 
45. Reddy VR, Annamalai T, Narayanan V and Ramanathan A: Hypermethylation of promoter region of LATS1 - a CDK interacting protein in oral squamous cell carcinomas - a pilot study in India. Asian Pac J Cancer Prev 16: 1599-1603, 2015.

46. Karamitopoulou E, Zlobec I, Patsouris E, Peros G and Lugli A: Loss of E-cadherin independently predicts the lymph node status in colorectal cancer. Pathology 43: 133-137, 2011.

47. Li L, Fang R, Liu B, Shi H, Wang Y, Zhang W, Zhang X and Ye L: Deacetylation of tumor-suppressor MST1 in Hippo pathway induces its degradation through HBXIP-elevated HDAC6 in promotion of breast cancer growth. Oncogene 35: 4048-4057, 2016.

48. Rawat SJ and Chernoff J: Regulation of mammalian Ste20 (Mst) kinases. Trends Biochem Sci 40: 149-156, 2015.

49. Liang K, Zhou G, Zhang Q, Li J and Zhang C: Expression of hippo pathway in colorectal cancer. Saudi J Gastroenterol 20: 188-194, 2014.

50. Seidel C, Schagdarsurengin U, Blümke K, Würl P, Pfeifer GP, Hauptmann S, Taubert H and Dammann R: Frequent hypermethylation of MST1 and MST2 in soft tissue sarcoma. Mol Carcinog 46: 865-871, 2007.

51. Piccolo S, Dupont S and Cordenonsi M: The biology of YAP/TAZ Hippo signaling and beyond. Physiol Rev 94: 1287-1312, 2014.

52. Plouffe SW, Hong AW and Guan KL: Disease implications of the Hippo/YAP pathway. Trends Mol Med 21: 212-222, 2015.

53. Zhou D, Zhang Y, Wu H, Barry E, Yin Y, Lawrence E, Dawson D, Willis JE, Markowitz SD, Camargo FD, et al: Mst1 and Mst2 protein kinases restrain intestinal stem cell proliferation and colonic tumorigenesis by inhibition of Yes-associated protein (Yap) overabundance. Proc Natl Acad Sci USA 108: E1312-E1320, 2011

54. Cao JJ, Zhao XM, Wang DL, Chen KH, Sheng X, Li WB, Li MC Liu WJ and He J: YAP is overexpressed in clear cell renal cell carcinoma and its knockdown reduces cell proliferation and induces cell cycle arrest and apoptosis. Oncol Rep 32: 1594-1600, 2014.

55. Dong C, Wei KJ, Zhang WB, Sun H, Pan HY and Zhang L: LATS 2 induced by TNF-alpha and inhibited cell proliferation and invasion by phosphorylating YAP in oral squamous cell carcinoma. J Oral Pathol Med 44: 475-481, 2015.

56. He C, Lv X, Hua G, Lele SM, Remmenga S, Dong J, Davis JS and Wang C: YAP forms autocrine loops with the ERBB pathway to regulate ovarian cancer initiation and progression. Oncogene 34: 6040-6054, 2015.

57. Jerhammar F, Johansson AC, Ceder R, Welander J, Jansson A, Grafström RC, Söderkvist P and Roberg K: YAP1 is a potential biomarker for cetuximab resistance in head and neck cancer. Oral Oncol 50: 832-839, 2014.

58. Konsavage WM Jr, Kyler SL, Rennoll SA, Jin G and Yochum GS Wnt/ $\beta$-catenin signaling regulates Yes-associated protein (YAP) gene expression in colorectal carcinoma cells. J Biol Chem 287 11730-11739, 2012.
59. Yuan H, Liu H, Liu Z, Zhu D, Amos CI, Fang S, Lee JE and Wei Q: Genetic variants in Hippo pathway genes YAPI, TEADI and TEAD4 are associated with melanoma-specific survival. Int J Cancer 137: 638-645, 2015.

60. Zhao J, Li X, Yang Y, Zhu D, Zhang C, Liu D, Wu K and Zhao S Effect of YAP1 silencing on esophageal cancer. Onco Targets Ther 9: 3137-3146, 2016.

61. Li P, Sun D, Li X, He Y, Li W, Zhao J, Wang Y, Wang H and Xin Y: Elevated expression of Nodal and YAP1 is associated with poor prognosis of gastric adenocarcinoma. J Cancer Res Clin Oncol 142: 1765-1773, 2016.

62. Liao T, Wen D, Ma B, Hu JQ, Qu N, Shi RL, Liu L, Guan Q, Li DS and Ji QH: Yes-associated protein 1 promotes papillary thyroid cancer cell proliferation by activating the ERK/MAPK signaling pathway. Oncotarget: Feb 14, 2017 (Epub ahead of print). doi.org/10.18632/oncotarget.14319.

63. Pan Y, Robertson G, Pedersen L, Lim E, Hernandez-Herrera A, Rowat AC, Patil SL, Chan CK, Wen Y,Zhang X, et al: miR-509-3p is clinically significant and strongly attenuates cellular migration and multi-cellular spheroids in ovarian cancer. Oncotarget 7 : 25930-25948, 2016.

64. Xu R, Zeng G, Gao J, Ren Y, Zhang Z, Zhang Q, Zhao J, Tao H and Li D: miR-138 suppresses the proliferation of oral squamous cell carcinoma cells by targeting Yes-associated protein 1 . Oncol Rep 34: 2171-2178, 2015.

65. Xiao L, Zhou H, Li XP, Chen J, Fang C, Mao CX, Cui JJ, Zhang W, Zhou HH, Yin JY, et al: MicroRNA-138 acts as a tumor suppressor in non small cell lung cancer via targeting YAP1. Oncotarget 7: 40038-40046, 2016.

66. Lee KW, Lee SS, Kim SB, Sohn BH, Lee HS, Jang HJ, Park YY, Kopetz S, Kim SS, Oh SC, et al: Significant association of oncogene YAP1 with poor prognosis and cetuximab resistance in colorectal cancer patients. Clin Cancer Res 21: 357-364, 2015.

67. Song S, Honjo S, Jin J, Chang SS, Scott AW, Chen Q, Kalhor N, Correa AM, Hofstetter WL, Albarracin CT, et al: The Hippo coactivator YAP1 mediates EGFR overexpression and confers chemoresistance in esophageal cancer. Clin Cancer Res 21: 2580-2590, 2015.

68. Touil Y, Igoudjil W, Corvaisier M, Dessein AF, Vandomme J, Monté D, Stechly L, Skrypek N, Langlois C, Grard G, et al: Colon cancer cells escape 5FU chemotherapy-induced cell death by entering stemness and quiescence associated with the c-Yes/YAP axis. Clin Cancer Res 20: 837-846, 2014.

69. Wang DY, Wu YN, Huang JQ, Wang W, Xu M, Jia JP, Han G, Mao BB and Bi WZ: Hippo/YAP signaling pathway is involved in osteosarcoma chemoresistance. Chin J Cancer 35: 47, 2016. 